\title{
Aspectos epidemiológicos e clínico-patológicos de um surto de miopatia nutricional em potros - relato de caso
}

\author{
[Epidemiological and clinical-pathological aspects of an outbreak of nutritional myopathy \\ in young horses - case report] \\ R.S. Albuquerque ${ }^{1}$, L.G. Ávila ${ }^{2}$, F.A. Batista ${ }^{2}$, R.C. Pupin ${ }^{2}$, \\ R.A.A. Lemos $^{2}$, M.A. Araújo ${ }^{2}$
}

${ }^{1}$ Programa de Residência - Universidade Federal de Mato Grosso do Sul - Campo Grande, MS ${ }^{2}$ Universidade Federal de Mato Grosso do Sul - Campo Grande, MS

\begin{abstract}
RESUMO
A miopatia nutricional é uma doença degenerativa que pode afetar os músculos esqueléticos e cardíaco, causada pela deficiência dietética de selênio e/ou vitamina E. Objetivou-se relatar a ocorrência de miopatia nutricional em dois potros Puro Sangue Inglês, criados de forma extensiva, com baixa disponibilidade de forragem e sem suplementação mineral. De um lote de nove animais de diferentes idades (cinco éguas adultas, uma potra lactente de três meses,uma mula e dois potros de 16 e 17 meses), apenas os dois últimos foram afetados. Clinicamente, havia decúbito lateral ou esternal, taquicardia, taquipneia, desidratação e dor à palpação muscular na região dos glúteos.O diagnóstico presuntivo de miopatia nutricional foi realizado por meio da associação dos sinais clínicos aos dados epidemiológicos.O animal 1 foi eutanasiado cinco dias após o atendimento devido à piora gradativa do quadro, e o animal 2 recuperou-se com o tratamento adotado. O diagnóstico foi confirmado com base nos exames complementares, nos achados de necropsia e na dosagem da concentração hepática de selênio. Este relato de caso alerta para o risco da ocorrência de miopatia nutricional em equinos, sobretudo jovens, sem acesso a pastagens ou feno de boa qualidade e sem suplementação mineral adequada.
\end{abstract}

Palavras-chave: vitamina E, selênio, potros, músculo

\begin{abstract}
Nutritional myopathy is a degenerative disease caused by the dietary deficiency of selenium and/or vitamin E that can affect skeletal and cardiac muscles. The objective of this study was to report the occurrence of nutritional myopathy in two Thoroughbred young horses, raised in pastures with low forage availability and no mineral supplementation. From a herd of nine animals of different ages (five adult mares, one threemonth-old nursing foal, one mule and two 16-and 17-month-old horses), only the last two were affected. Clinical signs were lateral or sternal recumbency, tachycardia, tachypnea, dehydration and muscle pain. Presumptive diagnosis of nutritional myopathy was made associating clinical signs and epidemiological data. Animal 1 was euthanized five days after the first evaluation due to clinical signs gets worse, and animal 2 recovered with the established treatment. Diagnosis was confirmed with complementary exams, necropsy findings and levels of hepatic selenium. This paper alerts to the risk of nutritional myopathy occurrence in horses, mainly young animals, which are not ingesting good quality hay or green forage and do not receive appropriate mineral supplementation.
\end{abstract}

Keywords: Vitamin E, selenium, young horses, muscle

INTRODUÇÃO músculo branco, é uma enfermidade

A miopatia nutricional,também conhecida como miodegeneração nutricional, miodegeneração distrófica, miodistrofia nutricional ou doença do miodegenerativa hiperaguda, aguda ou subaguda dados músculos cardíaco e esqueléticos associada à deficiência de selênio (Cooper e Valentine,

Recebido em 22 de fevereiro de 2019

Aceito em 23 de outubro de 2019

E-mail: joaquimparreira@iftm.edu.br 
2016) e a menor grau de vitamina E (Higuchi et al., 1989).

$\mathrm{O}$ selênio e a vitamina $\mathrm{E}$ atuam como protetores celulares contra o estresse oxidativo causado pelos radicais livres, que podem danificara membrana celular por peroxidação dos lipídeos ou por dano às moléculas de proteína das mitocôndrias, do retículo endoplasmático e do citosol (Aleman, 2008; Cooper e Valentine, 2016). Quando há deficiência dessas substâncias, ocorre lesão da membrana celular e consequente alteração de permeabilidade, o que permite o influxo de cálcio para o citosol e o acúmulo nas mitocôndrias, resultando em hipercontração das miofibras e necrose segmentar (Constable et al., 2018).

Historicamente, a doença ocorre em animais jovens, sendo bovinos, ovinos e suínos os mais suscetíveis. Equinos são considerados moderadamente suscetíveis e, nessa espécie, animais de qualquer idade podem ser afetados (Cooper e Valentine, 2016), sobretudo os criados em pastagem sem regiões com baixas concentrações de selênio no solo (Losfted, 1997; Aleman, 2008; Valberg, 2017). Potros com maior crescimento e aqueles que se mantêm mais ativos no rebanho também são mais predispostos (Valberg, 2017).

Apesar da moderada suscetibilidade dos equinos a essa enfermidade, no Brasil há apenas a descrição de um surto (Amorin et al., 2011). Dessa forma, o objetivo deste trabalho foi relatar um surto de miopatia nutricional em potros criados de forma extensiva, com baixa disponibilidade de forragem e sem suplementação mineral, abordando-se os aspectos epidemiológicos, clínicos, anátomo-patológicos e o tratamento.

\section{RELATO DO CASO}

Foram atendidos, em uma propriedade rural no município de Campo Grande, Mato Grosso do Sul, dois potros da raça Puro Sangue Inglês, com queixa de decúbito de início súbito. $\mathrm{O}$ primeiro animal (1) era um macho de 17 meses, aproximadamente $350 \mathrm{~kg}$ e, segundo o responsável, estava em decúbito permanente há cerca de 18 horas; o segundo animal (2) era uma fêmea de 16 meses, pesando estimados $280 \mathrm{~kg}$ e em decúbito há seis horas.
Os potros estavam há seis meses nessa propriedade, em um lote com outros sete equídeos de diferentes idades (cinco éguas adultas, uma potra lactente de três meses e uma mula), que eram criados de maneira extensiva, em um pasto de 18 hectares de Uruchloa (Brachiaria) decumbens e com acesso a uma área pequena de Paspalum notatum intensamente pastejada. Diariamente, recebiam aveia (aproximadamente $2 \mathrm{~kg}$ ) e milho (cerca de $1 \mathrm{~kg}$ ), divididos em duas porções (início da manhã e final da tarde). Não recebiam suplementação mineral e a água era proveniente de bebedouro pilheta.

No exame físico, ambos apresentavam sinais clínicos semelhantes, caracterizados por decúbito lateral ou esternal (Fig.1A), taquicardia, taquipneia, desidratação e dor à palpação muscular na região dos glúteos. $\mathrm{O}$ animal 1 apresentava quadro mais grave, não sendo capaz de permanecer em posição quadrupedal, enquanto o animal 2 ainda era capaz de adotá-la com auxílio. Todos os demais parâmetros do exame físico apresentavam-se dentro dos limites de normalidade e os dois equinos mantinham apetite e capacidade de deglutição. Não havia indícios de alteração neurológica ou trauma e não foram encontrados ectoparasitas.

De acordo com o histórico e os achados de exame físico, suspeitou-se de miopatia nutricional. Amostras de sangue foram coletadas por venopunção jugular, em tubos com e sem anticoagulante, para realização de hemograma e bioquímica sérica (dosagem de albumina, aspartato amino transferase (AST), creatinaquinase $(\mathrm{CK})$, creatinina, gama glutamiltransferase (GGT) e uréia). Foi iniciado imediatamente o tratamento com vitamina $\mathrm{E}$ e selênio (Excell E, Vetoquinol, Brasil), na dose de 20mL/VO/BID (por 15 dias); vitamina B1 (Monovin B1, Vitamina B1 10\%, Laboratório Bravet Ltda., Brasil), na dose de 10mg/kg/IV/SID (por cinco dias), e flunixina meglumina, dose de $1,1 \mathrm{mg} / \mathrm{kg} / \mathrm{IV} / \mathrm{SID}$ (por três dias). Adicionalmente, na tentativa de restabelecer a posição quadrupedal, $\mathrm{o}$ animal 1 foi submetido à suspensão, utilizando-se talha e fitas de elevação.

As alterações observadas nos exames hematológicos incluíram aumento das atividades séricas de AST e CK, anemia microcítica normocrômica, neutrofilia e trombocitopenia em ambos os animais (Tab. 1). 
O tratamento instituído foi eficiente no animal 2, e, no segundo dia, este foi capaz de levantar-se sem auxílio e, a partir de então, foi gradativamente permanecendo mais tempo em posição quadrupedal (Fig. 1B). O animal 1 não apresentou melhora com a conduta adotada e, devido ao prognóstico desfavorável, confirmado pelos exames bioquímicos subsequentes (CK: 509.073,00UI/L e AST: 11.273,10UI/L), optou-se pela eutanásia no quinto dia após o diagnóstico presuntivo.

$\mathrm{O}$ animal 1 foi submetido à necropsia, e as alterações restringiram-se à musculatura esquelética dos membros torácicos e pélvicos e ao longuíssimo do dorso. Havia edema acentuado e palidez bilateral (Fig. 1C) nos músculos tríceps braquial, subescapular, vasto lateral, semitendinoso e semimembranoso. Microscopicamente, essas áreas constituíam-se de múltiplos focos extensos de necrose, caracterizados por aumento da eosinofilia das miofibras, com segmentação, perda das estrias e leve infiltrado de macrófagos e neutrófilos fagocitando os restos necróticos. Em um dos fragmentos do membro pélvico esquerdo, havia também áreas multifocais de hemorragia.

Foi realizada a avaliação da concentração de selênio no fígado do animal 1 por meio de espectrometria de absorção, sendo verificado valor de $0,084 \mu \mathrm{g} / \mathrm{g}$.

Tabela 1. Parâmetros hematológicos e bioquímicos, no primeiro dia de atendimento, de dois potros Puro Sangue Inglês, de 17 e 16 meses de idade (animais 1 e 2), com miopatia nutricional

\begin{tabular}{lccc}
\hline Parâmetros & Animal 1 & Animal 2 & Referência \\
\hline Hematócrito (\%) & 29,9 & 29,1 & 32 a 53 \\
Hemoglobina (g/dL) & 10,5 & 10,5 & 11 a 19 \\
V.C.M. (fL) & 33,6 & 34,8 & 37 a 58 \\
Leucócitos $\left(\mathrm{mm}^{3}\right)$ & 12.800 & 16.600 & 5.400 a 14.500 \\
Neutrófilos $\left(\mathrm{mm}^{3}\right)$ & 9.984 & 14.110 & 2.280 a 8.580 \\
Plaquetas $\left(\mathrm{mm}^{3}\right)$ & 46.000 & 92.000 & 100.000 a 350.000 \\
Albumina $(\mathrm{g} / \mathrm{dL})$ & 3,6 & 3,1 & 2,6 a 3,7 \\
AST (UI/L) & 450,3 & 336,1 & 58 a 94 \\
Creatinina (mg/dL) & 1,4 & 1,1 & 1,2 a 1,9 \\
CK (UI/L) & $4.371,0$ & $2.637,0$ & 2,4 a 23,4 \\
GGT (UI/L) & 43,7 & 19,1 & 4,3 a 13,4 \\
Ureia (mg/dL) & 42,3 & 43,7 & 21,4 a 51,4 \\
\hline
\end{tabular}

V.C.M: volume corpuscular médio; AST: aspartato amino transferase; CK: creatinaquinase; GGT: gama glutamiltransferase.
A suspeita diagnóstica baseou-se na epidemiologia, nos sinais clínicos e achados de necropsia e no exame histopatológico e foi confirmada pela dosagem da concentração hepática de selênio no animal 1 , que foi inferior ao mínimo considerado normal para a espécie $(1,05-3,50 \mu \mathrm{g} / \mathrm{g})($ Cooper e Valentine, 2016).

Apesar de todos os animais do lote serem submetidos ao mesmo manejo nutricional, somente dois casos foram observados. De acordo com Delesalle et al. (2017), 82\% dos casos acometem equinos com idade inferior a quatro anos, o que está de acordo com a idade dos animais acometidos nesse surto. Suspeita-se que o crescimento rápido predisponha a enfermidade nos equinos dessa idade devido à demanda excessiva de vitamina $E$ e selênio ou a uma transição bioquímica à medida que os tipos de fibra se desenvolvem para padrões adultos (Cooper e Valentine, 2016; Valberg, 2017). No entanto, nem todos os potros com baixos níveis séricos de selênio e vitamina $\mathrm{E}$ desenvolvem a doença, o que sugere que fatores individuais (como a carga de exercícios e outros estressores) também são importantes na patogênese (Delesalle et al., 2017). 


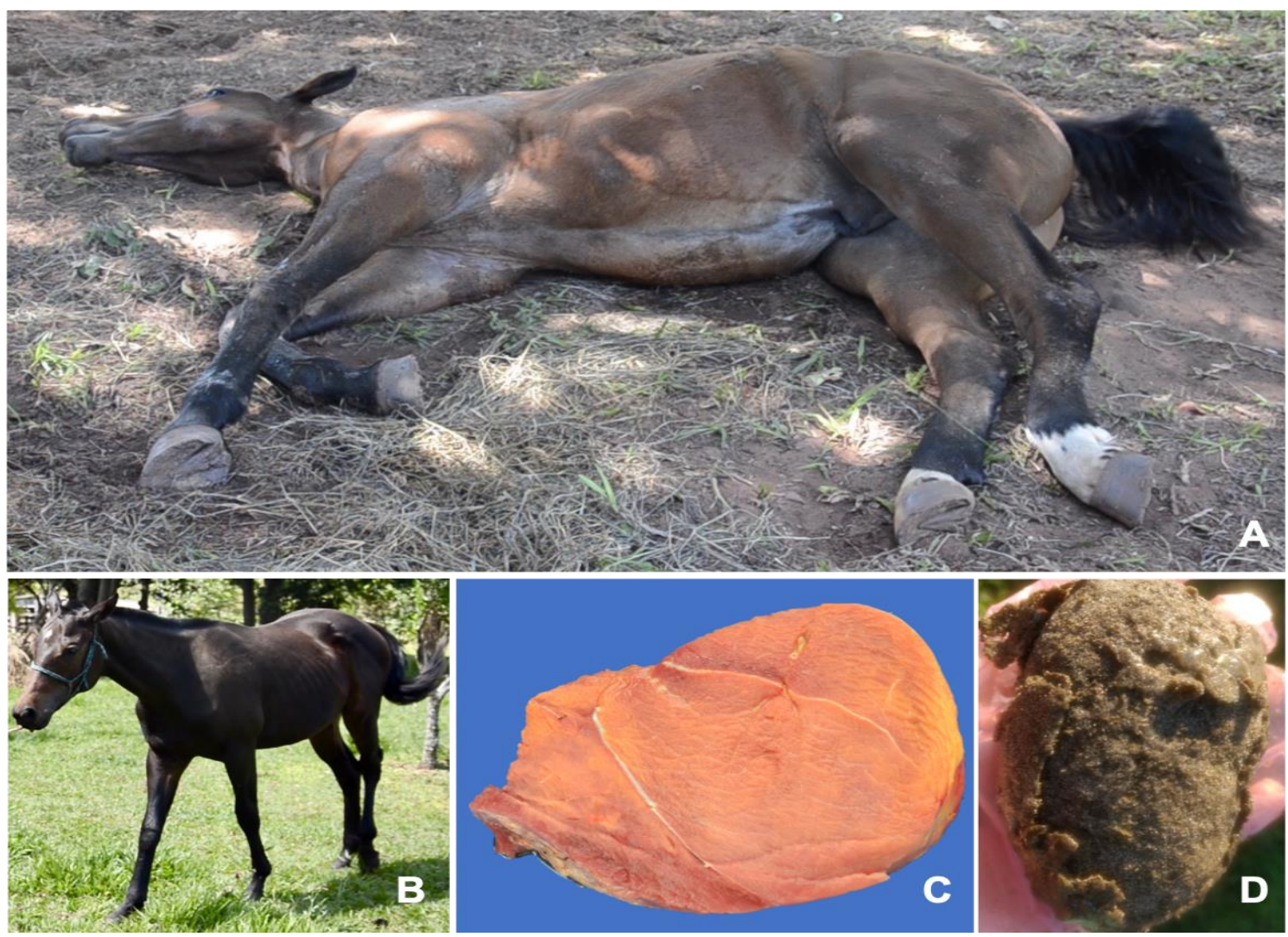

Figura 1. Miopatia nutricional em potros de 16 e 17 meses de idade, criados com baixa disponibilidade de forragem e sem suplementação mineral. (A) Animal 1 em decúbito lateral, no primeiro dia de atendimento. (B) Animal 2, no segundo dia após atendimento, evidenciando paresia do membro pélvico esquerdo (arrastar de pinças). (C) Lesão macroscópica animal 1 - músculo esquelético com palidez acentuada e difusa. (D) Amostra de fezes de uma égua adulta do mesmo lote dos potros doentes, contendo abundante quantidade de areia. Esse animal foi diagnosticado com sablose devido à ingestão de areia junto com a grama (Paspalum notatum) intensamente pastejada.

Sugere-se que, nesse surto, a dieta deficiente foi a causa da doença nos potros, uma vez que a disponibilidade de Paspalum notatum era baixa e nenhuma suplementação mineral era fornecida, estando a alimentação baseada apenas na quirera de milho e aveia oferecidas no cocho. Equídeos que não têm acesso regular a pastos verdes ou quando são alimentados com fenos armazenados por períodos prolongados ou de forma deficiente podem apresentar deficiência de vitamina $\mathrm{E}$ (Valberg, 2017). Outro fato que corrobora a deficiência da forragem na dieta foi o atendimento de duas éguas (uma dois meses antes, e outra uma semana após o surto) no Hospital Veterinário da Faculdade de Medicina Veterinária e Zootecnia da Universidade Federal de Mato Grosso do Sul (Famez - UFMS),com o diagnóstico de síndrome cólica por sablose, por terem ingerido areia na tentativa de pastejar nas poucas áreas com a presença de grama Paspalum notatum degradada(Fig. 1D).

Embora não tenha sido realizada a avaliação da concentração de selênio nos cereais e na pastagem que compunham a dieta, de maneira geral, no Brasil, o solo é relativamente pobre em selênio, assim como os grãos e as dietas peletizadas. Plantas altamente fertilizadas, leguminosas e aquelas que crescem em solos ácidos e pobremente aerados tendem a ter menor quantidade de selênio (Aleman, 2008; Oliveira, 2012).

Devido às funções sobrepostas do selênio e da vitamina $E$, nem sempre é possível conhecer a importância etiológica específica de um desse sem causar a miopatia nutricional, assim, conforme utilizado nos animais do presente surto, a recomendação é tratamento com associação de 
selênio e vitamina E (Constable et al., 2018). Na forma cardíaca da miopatia nutricional, o dano ao miocárdio costuma ser extenso e incompatível com a vida. Por outro lado, a forma esquelética é geralmente passível de tratamento, embora o prognóstico para a recuperação clínica seja reservado e dependa frequentemente de complicações secundárias, como doença respiratória (Valberg, 2015).

Ressalta-se a importância de um exame físico criterioso, uma vez que os sinais clínicos de miopatia nutricional podem ser inespecíficos e podem ser confundidos com cólica, insuficiência cardíaca, depressão ou botulismo. Em potros e cavalos adultos jovens, as características mais comuns são rigidez e paresia, como ocorreu no presente surto, enquanto em animais adultos, o trismo e a incapacidade de apreensão e mastigação são mais comuns, embora a marcha rígida e o início súbito de decúbito também sejam possíveis (Cooper e Valentine, 2016).

Os principais diagnósticos diferenciais que devem ser incluídos quando há evidência de lesão muscular multifocal em equinos são: (1) intoxicação por antibióticos ionóforos, que foi excluída no presente surto, pois os animais não tinham contato com essas substâncias, e (2) miopatia pós-exercícios, que também foi excluída pelo fato de não haver histórico de que os animais tivessem sido submetidos a esforço físico excessivo nos dias anteriores ao início dos sinais (Cooper e Valentine, 2016). A intoxicação por plantas do gênero Senna, que é associada à necrose muscular em várias espécies, é mais associada a lesões hepáticas em equinos, causando necrose aguda (Oliveira-Filho et al., 2013).

\section{CONCLUSÃO}

Este relato de caso alerta para o risco da ocorrência de miopatia nutrional em equinos, sobretudo jovens, sem acesso a pastagens ou feno de boa qualidade e sem suplementação mineral adequada. Essa enfermidade deve ser incluída como diagnóstico diferencial em casos de paresia e decúbito em equinos.

\section{REFERÊNCIAS}

ALEMAN, M. A review of equine muscle disorders. Neuromuscular Disord.,v.18, p.277-287, 2008.

AMORIN, R.M.; RINO, A.S.; DAL-PAI-SILVA, M. et al. Aspectos morfológicos de biópsias musculares em equinos com miopatia sob forma de surto. Pesqui. Vet. Bras., v.31, p.579-585, 2011.

CONSTABLE, P.D.; HINCHCLIFF, P.W.; DONE, S.H, GRÜNBERG, W. Diseases of the musculoskeletal system. In: _. Veterinary medicine: a textbook the diseases of cattle, horses, sheep, pigs, and goats. 11.ed. St. Louis Missouri: Elsevier, 2018. cap.15, p.13721539.

COOPER, B.J.; VALENTINE, B.A. Muscle and tendon. In: MAXIE, M.G. Jubb, Kennedy, and Palmer's pathology of domestic animals. 6.ed. Philadelphia: Saunders, 2016. v.1, cap.3, p.165-248.

DELESALLE, C.; BRUIJN, M.; WILMINK, S. et al. White muscle disease in foals: focus on selenium soil content. A case series. BMC Vet. Res., v.13, p.121, 2017.

HIGUCHI, T.; ICHIIJO, S.; OSAME, S.; OHISHI, H. Studies on serum selenium and tocopherol in white muscle disease of foal. Nippon JuigakuZasshiv, v.51, p.52-59, 1989 .

LOFSTEDT, J. White muscle disease of foals. Vet. Clin. N. Am. Equine Pract., v.13, p.169-85, 1997.

OLIVEIRA, T.F.B. Efeitos de diferentes níveis e fontes de selênio no desempenho e características de carcaça de frangos de corte. 2012. 20f. Dissertação (Mestrado em Zootecnia) - Universidade Federal de Lavras, Lavras, MG.

OLIVEIRA-FILHO, J.P.; CAGNINI, D.Q.; BADIAL, P.R.; PESSOA, M.A.; DEL PIERO, F. Hepato encephalopathy syndrome dueto Cassia occidentalis (Leguminosae, Caesalpinioideae) see dingestion in horses. Equine Vet. J., v.45, p.240-244, 2013.

VALBERG, S.J. Diseases of muscle. In: SMITH, B.P. Large animal internal medicine. 5.ed. St. Louis Missouri: Elsevier, 2015. cap.42, p.1276-1308.

VALBERG, S.J. Muscular system.In: WALDRIDGE, B.M. Nutrition almanagement of equine diseases and special cases. Iowa: Wiley Blackwell, 2017. cap.4, p.51-71. 